\title{
PIWI-interacting RNAs: new biomarkers for diagnosis and treatment of breast cancer
}

\author{
Parisa Maleki Dana ${ }^{1}$, Mohammad Ali Mansournia ${ }^{2}$ and Seyyed Mehdi Mirhashemi ${ }^{3^{*}}$
}

\begin{abstract}
Cancer is one of the most important reasons of mortality in the world. However, there are several therapeutic platforms to treat patients who suffering from cancer common treatments such as surgery, chemotherapy and etc. The current therapeutic approaches are related to some limitations. Hence, more understanding about molecular mechanisms that involved in cancer particularly in breast cancer pathogenesis, could contribute to provide better therapeutic platforms. Recently, non-coding RNAs such as microRNAs have attracted researchers' attention in the field of cancer due to their functions in gene expression's regulation and functional interactions with other molecules. Interestingly, great advances in next-generation sequencing lead to considering other roles for another non-coding RNAs subgroup called PIWI-interacting RNAs (piRNAs) in addition to their functions in the germline. Novel studies investigated the role of piRNAs in several cancers including lung cancer, hepatocellular carcinoma, gastric cancer, multiple myeloma and colorectal cancer. Hopefully, based on new findings, piRNAs may be a potential biomarker which can be used as a tool to diagnose or treat breast cancer. Thus, this review aimed to discuss the role of piRNAs in breast cancer progression and metastasis as well as its molecular mechanisms.
\end{abstract}

Keywords: piRNA, Breast cancer, Epigenetic regulations

\section{Background}

Breast disorders are very important disorders among women [1]. Among them, Breast cancer is the most common malignancy among women and it is the principle cause of women's death all over the world. In spite of great progress in the field of cancer, breast cancer is still a serious health problem among women which has complicated properties heterogeneously and shows a number of biological and clinical manifestations [2-4]. Breast cancer has been categorized into five groups based on expression patterns of three receptors: the estrogen receptor, progesterone receptor and human epidermal growth factor receptor. This categorization was a helpful way in order to predict the outcome and choose the best

\footnotetext{
*Correspondence: mirhashemismm@gmail.com; sm.mirhashemi@qums.ac.ir

${ }^{3}$ Metabolic Diseases Research Center, Research Institute for Prevention

of Non-Communicable Diseases, Qazvin University of Medical Sciences, Qazvin, Iran

Full list of author information is available at the end of the article
}

treatment option $[5,6]$. Mutations in BRCA1 and BRCA2 are some examples of genomic instabilities which are the most prominent cause of breast cancer [7-9]. Several studies indicated that a variety of techniques could be used in the treatment of different cancers such as breast cancer (i.e., cell-, gene-, and nanotechnology-based therapies) [10-17]. Despite emerging new and effective therapeutic platforms in the treatment of breast cancer, new approaches are needed $[18,19]$. In this regard, it seems that more understanding of cellular and molecular pathways involved in breast cancer pathogenesis could contribute to the development of new therapies [18].

In the past, scientists called $98 \%$ non-protein coding human genome as "junk" DNA. These DNAs produce RNAs which are not translated into proteins. This group is known as non-coding RNAs (non-encoding RNAs) which has two main subgroups: regulatory non-coding RNAs and housekeeping non-coding RNAs. The regulatory non-coding RNAs are also sorted into two subdivisions by their length: short chain non-coding RNAs and

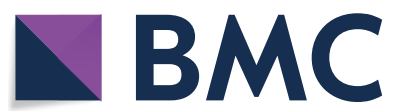

(c) The Author(s) 2020. This article is licensed under a Creative Commons Attribution 4.0 International License, which permits use, sharing, adaptation, distribution and reproduction in any medium or format, as long as you give appropriate credit to the original author(s) and the source, provide a link to the Creative Commons licence, and indicate if changes were made. The images or other third party material in this article are included in the article's Creative Commons licence, unless indicated otherwise in a credit line to the material. If material is not included in the article's Creative Commons licence and your intended use is not permitted by statutory regulation or exceeds the permitted use, you will need to obtain permission directly from the copyright holder. To view a copy of this licence, visit http://creativeco mmons.org/licenses/by/4.0/. The Creative Commons Public Domain Dedication waiver (http://creativecommons.org/publicdomain/ zero/1.0/) applies to the data made available in this article, unless otherwise stated in a credit line to the data. 
long chain non-coding RNAs. Short chain non-coding RNAs include small interfering RNAs (siRNAs), microRNAs (miRNAs), and piwi-interacting RNAs (piRNAs) [20]. Moreover, long chain non-coding RNAs are known as long non-coding RNAs (lncRNAs) and circularRNAs $[20,21]$. Recently, it has been revealed that non-coding RNAs have considerable roles in modifying epigenetics and regulating gene-level and chromosome-level expressions in order to cell differentiation controlling [22-24]. piRNAs are RNA molecules with the estimated size of $26-31 \mathrm{nt}$ binding to Piwi proteins $[25,26]$. The Piwi protein with the polycomb group proteins (PcGs) together bind to genomic PcG response elements in order to act as a regulatory factor. Therefore, piRNAs have a regulatory function in the body [27]. PiRNAs are classified into 3 group's base on their origin: transposon-derived piRNA, IncRNA-derived piRNAs, and mRNA-derived piRNAs. Besides, there are two sub-clusters for piRNAs; one of them acts in premeiotic germ cells (pre-pachytene piRNAs) and another one function in meiosis and haploid spermatid stage (pachytene piRNAs). The molecular features of both of these piRNAs are the same but pre-pachytene piRNAs cluster is totally different and has repetitive sequence elements [28]. piRNA-induced silencing complexes are produced by binding of piRNAs to PIWI proteins which generate a germline-specific member of the Argonaute family acting in silencing genes occurred by small RNAs [29].

piRNA-induced silencing complexes function by suppressing transposons during transcription and posttranscription leading to protection of the integrity of the germline genome. Moreover, regulation of cellular genes is another role of piRNAs in a variety of organisms [30-32]. PIWI-piRNA pathway acts both in inside and outside the germline. Additionally, these RNAs can recognize "self" and "nonself" genes and regulate the latter [33]. PIWI protein genes also exist in Drosophila and mouse; (ago3, aubergine (aub), and piwi), (MIWI, MIWI2, and MILI) are their distinct genes respectively. It is observed in these eukaryotes that PIWI proteins are involved in transposon silencing, undeniable function in gonadal development, male and female fertility, DNA methylation and etc. [34]. In addition to gonadal functions of PIWIs, they play roles in somatic tissues, especially stem cells. Up to now, four human PIWIs have been identified including HIWI (also known as PIWIL1), HILI (also known as PIWIL2), HIWI2 (also known as PIWIL4) and HIWI3 (also known as PIWIL3) [31]. Recent findings investigated the role of piRNAs in several cancers including lung cancer [35], hepatocellular carcinoma [36], gastric cancer [37], multiple myeloma [38] and colorectal cancer [39]. Hopefully, based on new research, piRNAs may be potential biomarkers which can be used as a tool to diagnose or treat breast cancer. Thus, this review aimed to discuss the role of piRNAs in breast cancer progression and metastasis as well as its molecular mechanisms.

\section{PiRNA biosynthesis}

While the transcription of transposon-derived piRNAs occurs from both genomic strands, sense and antisense piRNAs can be generated. While the origin of mRNAderived piRNAs is the $3^{\prime}$ untranslated regions of mRNAs, the IncRNAs-derived piRNAs originate from the entire lncRNA transcript [40]. Unlike miRNAs and siRNAs which are dependent on RNAse III Dicer for their maturation, piRNA biogenesis is a Dicer-independent process $[41,42]$. Additional post-transcriptional processes are necessary for the full maturation of piRNAs precursors. The primary synthesis and 'ping-pong' amplification are the two mechanisms which are used after the transcription in order to produce mature piRNAs [43]. In the simplest scenario, in gonad somatic cells of Drosophila, riboendonuclease Zucchini cleaves the primary transcript at first. After the incorporation of $3^{\prime}$ fragment in PIWI proteins, it is trimmed to its final length by a $3^{\prime}$ to $5^{\prime}$ exonuclease. The enzyme Hen 1 methylate the $2^{\prime}$ hydroxy group of the $3^{\prime}$ end. Meanwhile, $5^{\prime}$ end residue of incorporated piRNA in PIWI has a strong bias for the residues of uridine. Then, piRNAs bind PIWI proteins and form piRNA/PIWI complexes [44]. Finally, these complexes migrate to the nucleus where they can

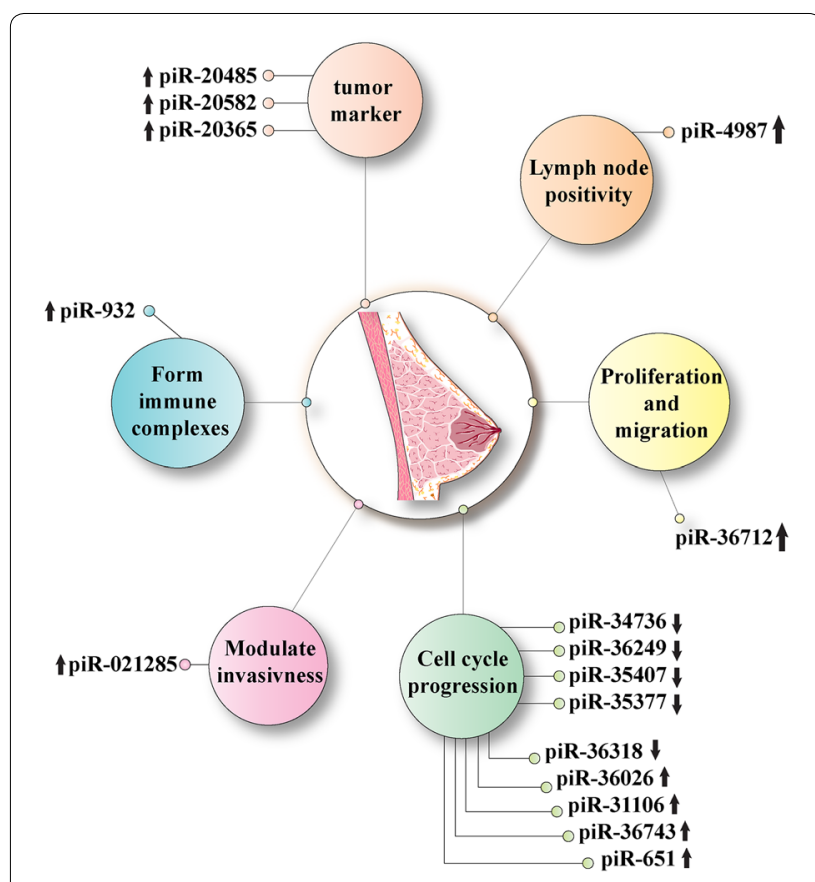

Fig. 1 Factors related to PIWI proteins and piRNAs in breast cancer 
mobilize the silencer machinery and block their target gene transcription. Therefore, heterochromatin which is transcriptionally silent will be established through the piRNA-mediated recruitment of histone methyltransferases [45]. In the cytoplasm, the ping-pong mechanism amplifies the accumulation of piRNAs after the production of primary piRNA [44]. Unlike the primary synthesis which is related to PIWI proteins, in this process, piRNA/Ago3 or piRNA/Aub complexes are formed. An RNA sequence will be generated by the piRNA/Ago3 complex which acts as a substrate used for producing new piRNA and the generated piRNA can load an Aub protein [46]. In fact, through an amplifying mechanism, the products of piRNAs result in the formation of substrate for other functional piRNAs [47]. While studies indicated that 'ping-pong' mechanism exists in zebrafish, D. melanogaster and primitive animals, findings reveal that the biogenesis of piRNAs in mice is not dependent on the 'ping-pong' cycle [47, 48].

As a mechanism which is firstly explained in ovarian germline of fly, the endonucleolytic action of cytosolic PIWI leads to the formation of two cleavage fragments. Then, new mature piRNA is produced through the participation of the downstream fragment in biogenesis pathway of piRNA. Noteworthy, PIWI slicing generates $5^{\prime}$ end of secondary piRNAs [44, 49]. Moreover, it is reported that the downstream cleavage fragment can be the origin of an extensive biogenesis of piRNAs [50-52]. In inchworming process, the fragment produces other non-overlapping piRNAs in a direction occurring from $5^{\prime}$ to $3^{\prime}$ [51]. Inchworming-produced primary piRNAs load into PIWI proteins of fly nucleus. Two PIWI proteins of mouse have been showed to have a similar association. In diverse species, biogenesis of piRNA happens near the mitochondrial surface, and different mitochondrial membrane-anchored factors are involved [53]. In mice, two cytoplasmic PIWI proteins including MILI, and MIWI, receive processed pachytene piRNAs at intermitochodrial cement (IMC) [53].In fact, what ensures that transposons remain silenced is the relation between cytoplasmic MILI and nuclear MIWI2 in the mouse embryonic male germline [54]. Moreover, the slicer activity of MILI has been reported to be essential in the production of MIWI2-associated piRNAs [55]. In a study of Yang et al. [56], it is shown that transcript endonucleolytic slicing which is done by cytosolic PIWI proteins of mouse, MILI, stimulates its $5^{\prime} \rightarrow 3^{\prime}$ processing. This event eventually leads to the production of non-overlapping fragments which are new piRNAs. Then, new piRNAs accumulate in nuclear MIWI2 and cytosolic MILI. Exonuclease domain-containing 1 (EXD1) is found to be the partner of TDRD12 which is a factor for the biogenesis of MIWI2 piRNA. Despite the inactivity of EXD1 as a nuclease, this factor plays its role in PET (PIWI-EXD1Tdrd12) complex as an adaptor of RNA. Altogether, this study concluded that PIWI stimulates the piRNA biogenesis and EXD1 enhances the production of piRNAs and ensures the effective entry of small RNAs to the PIWI proteins of nucleus [56].

\section{PiRNAs and cancer: molecular mechanisms}

In addition to PIWI proteins, piRNAs have significant roles in the carcinogenesis. Reproductive tissues express a great number of piRNAs. PiRNAs are also expressed in brain tissue as well as exosomes which are derived from the human plasma $[57,58]$. While miRNAs serve as the regulator of post-transcriptional activities, piRNAs are considered to act as the epigenetic regulator which is involved in angiogenesis, invasiveness, growth and metastasis of tumors $[59,60]$. Up to now, several studies concerned with the role of piRNAs in different processes which are involved in cancer.

PiR-651 has been shown to play a role in carcinogenesis through affecting apoptosis, proliferation, and migration. This piRNA is concluded to be overexpressed in several cancer cell lines such as lung, colon, gastric, breast cancer, hepatic carcinoma and mesothelioma. Moreover, it is found that the inhibitor of piR-651 can make cancer cells stop in G2/M phase. Indeed, due to the impacts of the piRNA pathway on the balance of cell division and self-renewal, any interruption in this pathway may make an effect on the progression of cancer. There are several studies indicating that the expression of piRNAs is decreased in multiple cancers resulting in the proliferation of cancer cells and progression of tumors [61]. As the piR-55490 is downregulated in lung cancer, research indicates that the proliferation of lung cancer cells can be reduced through the recovery of this piRNA [62]. Similar to what miRNAs do, piR-55490 decreases the decay of mTOR mRNA through binding to its $3^{\prime}$ UTR; thus, inhibiting Akt/mTOR signaling in lung cancer cells. In other words, piRNA targets oncogenic mRNA and leads to the suppression of tumor cells [62].

Novel research which is concerned with somatic roles of piRNAs has revealed that piRNAs may be involved in the regulation of gene expression by histone modification and DNA methylation [31, 63-65]. Meanwhile, DNA hypomethylation, histones hypoacetylation and gene-specific DNA hypermethylation are general epigenetic changes occurred in cancer leading to R-ras and cyclin D2 oncogenes activation as well as silencing RB1 and p16 tumor suppressor genes $[59,66]$. PIWIL4 (MIWI2) embedded in the nucleus leads to the methylation of retrotransposons promoter sequences and suppress them through methylation of de novo DNA in male mice before birth. Furthermore, by mutating 
MIWI2 and MIWI, retrotransposon promoters methylation will be lost in the mouse testes $[67,68]$. In several types of cancer such as lung, breast, colorectal, and stomach cancer, piR-1245 is reported to be overexpressed and considered to be involved in the carcinogenesis [69]. In colorectal cancer, this piRNA has been observed to regulate the progression of the tumor by targeting ATF3, BTG1, DUSP1, FAS, NFKBIA, UPP1, SESN2, TP53INP1 and MDX1 and associated with poor differentiation and metastasis [70]. While DNMT3L/ PIWIL2/TDRD1 complex can cause DNA methylation loss at transposons (LINE1 and IA), data has shown that in primary tumors of the testicle, transcriptional silencing is linked to the methylation of $5^{\prime}$ end promoter $\mathrm{CpG}$ in different genes including PIWIL1, PIWIL2, PIWIL4 and TDRD1 [71].

There is a theory explaining that piRNAs and PIWI proteins may lead to a characteristic found in cancers, aberrantly "stem-like" state. This stem-like state is occurred by the of PIWI-piRNA complexes that lead to genomic silencing following the aberrant methylation of DNA. Moreover, cancer cells which are similar to stem cells have shown to gain metastatic features as well as undergoing epithelial-mesenchymal transition. Despite the fact that epigenetic aberrancies are important tumor tissues properties, they are not well-understood yet. Emerging evidence collected from different types of tumors has suggested that cancers reflect the epigenetic state of adult progenitor cells [72]. Moreover, inhibiting mechanisms affecting the hypermethylation of DNA is similar to progenitor cells [73]. However, in progenitor cells, DNA methylation is responsible for silencing the differentiation genes, promoter site of tumor suppressor genes are the regions where the hypo-methylation occurred in cancer [73]. In stem cells, differentiation genes are silenced by EZH2 methyltransferase which mediates repressive histone 3 lysine 27 tri-methylation mark [74]. Furthermore, overexpression of EZH2 is observed in many cancers such as breast and prostate cancer which are associated with tumor aggressiveness [75]. These findings together may confirm that cancers have an aberrantly "stem-like" epigenetic state [76]. Findings have shown that piRNAs are considered to take part in different mechanisms involved in cancer including tumor cells proliferation, apoptosis, cancer spreading, and invasion and possibly be a potential biomarker for prognosis and diagnosis of cancer. The apoptosis-inducing role of piRNAs and their ability to prevent cell proliferation has been investigated in various tumors such as breast cancer, bladder cancer, multiple myeloma, gastric cancer, glioma and etc. The inhibitory function of piRNA on metastasis and invasion has been also shown in breast cancer, clear cell renal cell carcinoma, gastric cancer, and hepatocellular carcinoma [77].

\section{PiRNAs and breast cancer}

For the first time, Fu et al. [78] found that epigenetic functions occurring by piRNAs are able to make an effect on cancer-related pathways which are also involved in human breast cancer. Although their findings were restricted to one cell line, it is suggested to be capable to affect various genes methylation in MCF7. Indeed, the results showed that certain piRNAs, like miRNAs associated with cancer, probably target multiple genes thus any irruption in their function may lead to serious consequences such as several downstream of cancerrelated mechanisms. Based on evidence gathered from this study, piR-021285 can modulate the invasiveness of human breast cancer through methylation of the proinvasive ARHGAP11A gene at CpG site which is existed in the region of $5^{\prime} \mathrm{UTR} /$ first exon. Consequentially, the expression of pro-apoptotic mRNA will be decreased and apoptosis will be inhibited.

In a recent study, it is observed that piRNA-36,712 level in breast tumor tissues was significantly lower than in healthy tissues. In addition, low levels of this piRNA were related to poor outcome in breast cancer patients. Several studies showed that a retroprocessed pseudogene of SEPW1 "SEPW1P" produces RNAs which have interaction with piRNA-36,712. Thus, the competition of SEPW1 mRNA with SEPW1P RNA for microRNA-7 and microRNA-324 leads to SEPW1 suppression. Moreover, downregulation of piRNA-36,712 resulting in an increase in SEPW1 expression may inhibit P53 which contributes to Slug upregulation and P21 and E-cadherin levels reduction. Altogether, these alterations cause to promote the proliferation of cancer cells, invasion and migration. Besides, piRNA-36,712 can amplify the effects of chemotherapeutic agents, paclitaxel and doxorubicin in breast cancer. These findings implicate that piRNA36,712 is a new tumor suppressor which can be used in order to provide a prognosis and treat breast cancer patient [79].

In another study, the role of piRNAs in human breast cancer cells was examined. Using statistical analysis (Wilcoxon Mann-Whitney test) revealed a tumor-specific pattern containing 8 piRNAs which are expressed differentially. Five of these piRNA expression levels were lower in breast cancer tissues including DQ596670, DQ598183, DQ597341, DQ598252 and DQ596311 and three of them had higher expression levels in comparison with normal tissues, including DQ598677, DQ597960 and DQ57099 4. Recent research implicated that piRNAs have a role similar to miRNAs as they enhance to the formation of specific RNA silencing complexes (pi-RISC) promoting 
suppression of RNAs through an incomplete base-pairing between two of them [80, 81]. In Rizzo et al. [82] study applying stringent thermodynamic parameters and binding energy thresholds, it is indicated that each piRNA differentially expressed in cancer tissues was complementary to 23 to 383 RNAs comprising: mRNAs, pseudogene transcripts and long ncRNAs. These mRNAs probably targeted by piRNAs encode proteins which mainly have functions in breast cancer important cellular processes including cell-to-cell signaling and interaction, cell death and survival, cell cycle, and DNA replication and repair. Hu et al. [83] evaluated piRNA expression in tumor tissues and their non-tumoral counterparts by real-time PCR. The results indicated that four out of six piRNAs were up-regulated in breast cancer tissue including piR-4987, piR-20365, piR-20485, and piR-20582. Also, upregulation of piR-4987 expression was linked with lymph node positivity resulting in poorer outcome in breast cancer patients.

The most prominent prognostic indicator in breast cancer is axillary lymph node status which is also used to indicate the capability of the tumor to metastasis [84]. Based on this information, piR-4987 is a key player in progression, invasion and tumor spreading, probably have a regulatory effect on genes responsible for coding proteins. Thus, piRNA in cancer can regulate both oncogenes and anti-oncogenes. Another investigation on piR-651 revealed that its upregulation occurs in multiple cancers including breast cancer. This finding suggested that piR-651 may be an oncogene which was confirmed in gastric cancer. Guo et al. [39] used piR-651 inhibitor which leads to suppressing of gastric cancer cell growth. Their study implied that any disruption in the balance of this piRNA may result in a significant effect on tumor progression. The piR-932 expression has been also investigated in breast cancer. It is declared that piR-932 is significantly expressed higher in breast tumor tissues than in normal tissues. Furthermore, it can create immune complexes by immunoprecipitation with the help of PIWIL2. Also, in PIWIL2 + breast cancer stem cells, due to the methylation of Latexin promotor region (CpG island), Latexin expression levels are significantly lower than normal. These findings introduce a potential target which is the combination of piR-932 and PIWIL2. This complex, as a positive regulator promotes Latexin methylation and can be used in order to block the metastasis in breast cancer [85].

Table 1 Experimental studies that investigated the role of piRNAs in breast cancer

\begin{tabular}{|c|c|c|c|c|c|}
\hline PiRNA & Function & Type of breast cancer or its cell line & Model & Expression & References \\
\hline PiR-36712 & $\begin{array}{l}\text { Promotes cancer cell proliferation, invasion } \\
\text { and migration }\end{array}$ & Invasive breast ductal carcinoma & In vitro and In vivo & Underexpressed & {$[79]$} \\
\hline PiR-34736 & Progression of cell cycle & Invasive breast ductal carcinoma & In vitro & Underexpressed & {$[82]$} \\
\hline PiR-36249 & Progression of cell cycle & Invasive breast ductal carcinoma & In vitro & Underexpressed & {$[82]$} \\
\hline PiR-35407 & Progression of cell cycle & Invasive breast ductal carcinoma & In vitro & Underexpressed & {$[82]$} \\
\hline PiR-34377 & Progression of cell cycle & Invasive breast ductal carcinoma & In vitro & Underexpressed & {$[82]$} \\
\hline PiR-36318 & Progression of cell cycle & Invasive breast ductal carcinoma & In vitro & Underexpressed & {$[82]$} \\
\hline PiR-36026 & Progression of cell cycle & Invasive breast ductal carcinoma & In vitro & Overexpressed & {$[82]$} \\
\hline PiR-31106 & Progression of cell cycle & Invasive breast ductal carcinoma & In vitro & Overexpressed & {$[82]$} \\
\hline PiR-36743 & Progression of cell cycle & Invasive breast ductal carcinoma & In vitro & Overexpressed & {$[82]$} \\
\hline PiR-20582 & Tumor marker & Invasive breast ductal carcinoma & In vitro & Overexpressed & {$[83]$} \\
\hline PiR-4987 & Lymph node positivity & Invasive breast ductal carcinoma & In vitro & Overexpressed & {$[83]$} \\
\hline PiR-20365 & Tumor marker & Invasive breast ductal carcinoma & In vitro & Overexpressed & {$[83]$} \\
\hline PiR-20485 & Tumor marker & Invasive breast ductal carcinoma & In vitro & Overexpressed & {$[83]$} \\
\hline PiR-651 & Tumor progression & Bcap-37 cell line & In vitro & Overexpressed & {$[39]$} \\
\hline PiR-021285 & $\begin{array}{l}\text { Modulates } \\
\text { Breast cancer invasiveness }\end{array}$ & MCF7 breast cancer cell lines & In vitro & Overexpressed & {$[78]$} \\
\hline PiR-932 & $\begin{array}{l}\text { Promotes methylation of Latexin and form } \\
\text { immune complexes }\end{array}$ & Breast cancer stem cells(CSC) & In vitro & Overexpressed & {$[85]$} \\
\hline
\end{tabular}

thus piR-4987 overexpression leads to more aggressive breast cancer. Due to piRNAs role which is silencing transposons leading to genetic mutation and being associated with cancer, piRNAs may affect cancer by regulation of transposons. In addition, piRNAs
PIWI proteins and breast cancer

Similarly, PIWI proteins also have significant roles in different cancers such as breast cancer. In spite of extensive research about cancer, only recent articles have discussed PIWI proteins roles in this area [86]. PIWIL4 Gene is 
one of the upregulated genes in breast cancer which is highly expressed not only in breast cell lines but also in breast cancer samples. Findings have shown that in various cancers, PIWI proteins are expressed aberrantly. For instance, the overexpression of PIWIL2 has been observed in breast cancer [76, 87-92].

Moreover, Wang et al. [86] investigated the three active PIWI genes (PIWIL1, PIWIL2 and PIWIL4) expression. However, this study performed on six different types of breast cancer cell lines and the results showed that PIWIL1 expression level is significantly higher in four cancer cell line than in normal breast cell line. Additionally, PIWIL2 over-expressed in two cancer cell lines. Furthermore, PIWIL4 has remarkably higher expression levels in five cell lines. Another study also found that in 334 out of 1086 breast cases, PIWIL2 increased in breast cancer stem cells. Significantly, PIWIL2 has been linked to age, size of the tumor, histological type, tumor stage and lymph node metastasis. As mentioned earlier, PIWIL2 and piR-932 together can create immune complexes [85].

\section{Conclusions}

PiRNAs as a member of non-coding RNAs family have various roles in the germline as well as in somatic cells. It is found that piRNAs act as regulators in many cancers including breast cancer. Several studies have shown that piRNAs are involved in tumor cell's proliferation, apoptosis, invasion and metastasis. Although the research in this area is in its infancy, several papers implied that piRNAs can be used as biomarkers to early diagnosis of the breast cancer and may be used as a treatment option for this cancer (Fig.1 and Table 1). Expression patterns of piRNAs are different in breast cancer cell lines; in some of them, piRNAs expressions aberrantly increase but, in the others, piRNAs have been seen to be downregulated or they may be absent totally. Altogether, with further investigations, piRNAs may have a major role in the advancement of breast cancer research while there is a necessity to think beyond the usual breast cancer treatments. Thus, piRNAs may be beneficial targets for diagnosis, treatment or even preventing the metastasis of this cancer.

\section{Acknowledgements}

Not applicable.

\section{Authors' contributions}

SMM contributed in conception, design and drafting of the manuscript. PM-D and M-MM contributed in data collection and manuscript drafting. All authors read and approved the final manuscript.

\section{Funding}

Not applicable.
Availability of data and materials

Not applicable.

Ethics approval and consent to participate

Not applicable.

\section{Consent for publication}

Not applicable.

\section{Competing interests}

The authors declare no conflict of interest.

\begin{abstract}
Author details
${ }^{1}$ Research Center for Biochemistry and Nutrition in Metabolic Diseases, Kashan University of Medical Sciences, Kashan, I.R. of Iran. ${ }^{2}$ Department of Epidemiology and Biostatistics, School of Public Health, Tehran University of Medical Sciences, Tehran, Iran. ${ }^{3}$ Metabolic Diseases Research Center, Research Institute for Prevention of Non-Communicable Diseases, Qazvin University of Medical Sciences, Qazvin, Iran.
\end{abstract}

Received: 14 December 2019 Accepted: 7 March 2020

Published online: 23 March 2020

\section{References}

1. Mirhashemi SM, Sahmani M, Salehi B, Zavar Reza J, Taghizadeh M, Moussavi N, Badehnoosh B, Asemi Z. Metabolic response to omega-3 fatty acids and vitamin E Co-supplementation in patients with fibrocystic breast disease: a randomized, double-blind. Placebo-Control Trial Arch Iran Med. 2017:20(8):466-73.

2. Anastasiadi Z, Lianos GD, Ignatiadou E, Harissis HV, Mitsis M. Breast cancer in young women: an overview. Updates Surg. 2017:69(3):313-7.

3. Fitzmaurice C, Abate D, Abbasi N, Abbastabar H, Abd-Allah F, Abdelrahman $\mathrm{O}$, abdelalim a, abdoli a, abdollahpour i, abdulle asm, et al. global, regional, and national cancer incidence, mortality, years of life lost, years lived with disability, and disability-adjusted life-years for 29 cancer groups, 1990 to 2017: A systematic analysis for the Global Burden of Disease Study. JAMA Oncol. 2019;5(12):1749-68.

4. Akram M, lqbal M, Daniyal M, Khan AU. Awareness and current knowledge of breast cancer. Biol Res. 2017;50(1):33. https://doi.org/10.1186/ s40659-017-0140-9.

5. Sorlie T, Perou CM, Tibshirani R, Aas T, Geisler S, Johnsen H, Hastie T, Eisen $M B$, van de Rijn $M$, Jeffrey $S S$, et al. Gene expression patterns of breast carcinomas distinguish tumor subclasses with clinical implications. Proc Natl Acad Sci USA. 2001;98(19):10869-74.

6. Jafari SH, Saadatpour Z, Salmaninejad A, Momeni F, Mokhtari M, Nahand $J S$, Rahmati M, Mirzaei H. Breast cancer diagnosis: imaging techniques and biochemical markers. J Cell Physiol. 2018;233(7):5200-13.

7. Antoniou AC, Spurdle AB, Sinilnikova OM, Healey S, Pooley KA, Schmutzler RK, Versmold B, Engel C, Meindl A, Arnold N, et al. Common breast cancer-predisposition alleles are associated with breast cancer risk in BRCA1 and BRCA2 mutation carriers. Am J Hum Genet. 2008;82(4):937-48.

8. Chin K, DeVries S, Fridlyand J, Spellman PT, Roydasgupta R, Kuo WL, Lapuk A, Neve RM, Qian Z, Ryder T, et al. Genomic and transcriptional aberrations linked to breast cancer pathophysiologies. Cancer Cell. 2006;10(6):529-41.

9. Perou CM, Sorlie T, Eisen MB, van de Rijn M, Jeffrey SS, Rees CA, Pollack JR, Ross DT, Johnsen H, Akslen LA, et al. Molecular portraits of human breast tumours. Nature. 2000;406(6797):747-52.

10. Mirzaei H, Sahebkar A, Sichani LS, Moridikia A, Nazari S, Sadri Nahand J, Salehi H, Stenvang J, Masoudifar A, Mirzaei HR, et al. Therapeutic application of multipotent stem cells. J Cell Physiol. 2018;233(4):2815-23.

11. Hashemi Goradel N, Ghiyami-Hour F, Jahangiri S, Negahdari B, Sahebkar A, Masoudifar A, Mirzaei H. Nanoparticles as new tools for inhibition of cancer angiogenesis. J Cell Physiol. 2018;233(4):2902-10.

12. Mirzaei HR, Sahebkar A, Salehi R, Nahand JS, Karimi E, Jaafari MR, Mirzaei H. Boron neutron capture therapy: Moving toward targeted cancer therapy. J Cancer Res Therap. 2016;12(2):520-5. 
13. Mohammadi M, Jaafari MR, Mirzaei HR, Mirzaei H. Mesenchymal stem cell: a new horizon in cancer gene therapy. Cancer Gene Ther. 2016;23(9):285-6.

14. Mirzaei H, Sahebkar A, Avan A, Jaafari MR, Salehi R, Salehi H, Baharvand $H$, Rezaei A, Hadjati J, Pawelek JM, et al. Application of mesenchymal stem cells in melanoma: a potential therapeutic strategy for delivery of targeted agents. Curr Med Chem. 2016;23(5):455-63.

15. Mirzaei HR, Mirzaei H, Lee SY, Hadjati J, Till BG. Prospects for chimeric antigen receptor (CAR) gammadelta $T$ cells: a potential game changer for adoptive T cell cancer immunotherapy. Cancer Lett. 2016;380(2):413-23.

16. Harbeck N, Gnant M. Breast cancer. Lancet (London, England). 2017;389(10074):1134-50

17. Mirzaei H, Sahebkar A, Jaafari MR, Hadjati J, Javanmard SH, Mirzaei HR, Salehi R. PiggyBac as a novel vector in cancer gene therapy: current perspective. Cancer Gene Ther. 2016;23(2-3):45-7.

18. Boyages J. Radiation therapy and early breast cancer: current controversies. Med J Aust. 2017;207(5):216-22.

19. Sitt JC, Lui CY, Sinn LH, Fong JC. Understanding breast cancer screeningpast, present, and future. Hong Kong Med J. 2018;24(2):166-74.

20. Chaichian S, Shafabakhsh R, Mirhashemi SM, Moazzami B, Asemi Z. Circular RNAs: a novel biomarker for cervical cancer. J Cell Physiol. 2020;235(2):718-24.

21. Mirzaei H, Yazdi F, Salehi R, Mirzaei HR. SiRNA and epigenetic aberrations in ovarian cancer. J Cancer Res Ther. 2016;12(2):498-508.

22. Mirzaei H, Ferns GA, Avan A, Mobarhan MG. Cytokines and MicroRNA in coronary artery disease. Adv Clin Chem. 2017;82:47-70.

23. Gholamin S, Mirzaei H. GD2-targeted immunotherapy and potential value of circulating microRNAs in neuroblastoma. J Cell Physiol. 2018;233(2):866-79.

24. Keshavarzi M, Sorayayi S, Jafar Rezaei M, Mohammadi M, Ghaderi A, Rostamzadeh A, Masoudifar A, Mirzaei H. MicroRNAs-based imaging techniques in cancer diagnosis and therapy. J Cell Biochem. 2017;118(12):4121-8.

25. Grivna ST, Beyret E, Wang Z, Lin H. A novel class of small RNAs in mouse spermatogenic cells. Genes Dev. 2006;20(13):1709-14.

26. Lau NC, Seto AG, Kim J, Kuramochi-Miyagawa S, Nakano T, Bartel DP, Kingston RE. Characterization of the piRNA complex from rat testes. Science. 2006;313(5785):363-7.

27. Lin H. piRNAs in the germ line. Science. 2007;316(5823):397.

28. Wei JW, Huang K, Yang C, Kang CS. Non-coding RNAs as regulators in epigenetics (Review). Oncol Rep. 2017;37(1):3-9.

29. Hock J, Meister G. The Argonaute protein family. Genome Biol. 2008;9(2):210

30. Ishizu H, Siomi H, Siomi MC. Biology of PIWl-interacting RNAs: new insights into biogenesis and function inside and outside of germlines. Genes Dev. 2012;26(21):2361-73.

31. Ross RJ, Weiner MM, Lin H. PIWI proteins and PIWI-interacting RNAs in the soma. Nature. 2014;505(7483):353-9.

32. Stuwe E, Toth KF, Aravin AA. Small but sturdy: small RNAs in cellular memory and epigenetics. Genes Dev. 2014;28(5):423-31.

33. Malone CD, Hannon GJ. Small RNAs as guardians of the genome. Cell. 2009;136(4):656-68.

34. Iwasaki YW, Siomi MC, Siomi H. PIWI-interacting RNA: its biogenesis and functions. Annu Rev Biochem. 2015;84:405-33.

35. Martinez VD, Vucic EA, Thu KL, Hubaux R, Enfield KS, Pikor LA, BeckerSantos DD, Brown CJ, Lam S, Lam WL. Unique somatic and malignant expression patterns implicate PIWl-interacting RNAs in cancer-type specific biology. Sci Rep. 2015;5:10423.

36. Law PT, Qin H, Ching AK, Lai KP, Co NN, He M, Lung RW, Chan AW, Chan TF, Wong N. Deep sequencing of small RNA transcriptome reveals novel non-coding RNAs in hepatocellular carcinoma. J Hepatol. 2013;58(6):1165-73

37. Cui L, Lou Y, Zhang X, Zhou H, Deng H, Song H, Yu X, Xiao B, Wang W, Guo J. Detection of circulating tumor cells in peripheral blood from patients with gastric cancer using piRNAs as markers. Clin Biochem. 2011:44(13):1050-7.

38. Yan H, Wu QL, Sun CY, Ai LS, Deng J, Zhang L, Chen L, Chu ZB, Tang B, Wang $K$, et al. piRNA-823 contributes to tumorigenesis by regulating de novo DNA methylation and angiogenesis in multiple myeloma. Leukemia. 2015;29(1):196-206.
39. Cheng J, Guo JM, Xiao BX, Miao Y, Jiang Z, Zhou H, Li QN. piRNA, the new non-coding RNA, is aberrantly expressed in human cancer cells. Clin Chim Acta. 2011:412(17-18):1621-5.

40. Yu Y, Xiao J, Hann SS. The emerging roles of PIWI-interacting RNA in human cancers. Cancer Manag Res. 2019;11:5895-909.

41. Houwing S, Kamminga LM, Berezikov E, Cronembold D, Girard A, van den Elst H, Filippov DV, Blaser H, Raz E, Moens CB, et al. A role for Piwi and piRNAs in germ cell maintenance and transposon silencing in Zebrafish. Cell. 2007;129(1):69-82.

42. Nicholson AW. Ribonuclease III mechanisms of double-stranded RNA cleavage. Wiley Interdiscip Rev RNA. 2014;5(1):31-48.

43. Huang Y, Bai JY, Ren HT. PiRNAs biogenesis and its functions. Bioorg Khim. 2014;40(3):320-6.

44. Brennecke J, Aravin AA, Stark A, Dus M, Kellis M, Sachidanandam R, Hannon GJ. Discrete small RNA-generating loci as master regulators of transposon activity in Drosophila. Cell. 2007;128(6):1089-103.

45. Luteijn MJ, Ketting RF. PIWI-interacting RNAs: from generation to transgenerational epigenetics. Nat Rev Genet. 2013;14(8):523-34

46. Cheng Y, Wang Q, Jiang W, Bian Y, Zhou Y, Gou A, Zhang W, Fu K, Shi W. Emerging roles of piRNAs in cancer: challenges and prospects. Aging (Albany NY). 2019;11(21):9932-46.

47. Grimson A, Srivastava M, Fahey B, Woodcroft BJ, Chiang HR, King N, Degnan BM, Rokhsar DS, Bartel DP. Early origins and evolution of microRNAs and Piwi-interacting RNAs in animals. Nature. 2008:455(7217):1193-7.

48. Beyret $\mathrm{E}$, Liu N, Lin H. piRNA biogenesis during adult spermatogenesis in mice is independent of the ping-pong mechanism. Cell Res. 2012;22(10):1429-39.

49. Gunawardane LS, Saito K, Nishida KM, Miyoshi K, Kawamura Y, Nagami T, Siomi H, Siomi MC. A slicer-mediated mechanism for repeat-associated siRNA 5' end formation in Drosophila. Science. 2007;315(5818):1587-90.

50. Han BW, Wang W, Li C, Weng Z, Zamore PD. Noncoding RNA. piRNAguided transposon cleavage initiates Zucchini-dependent, phased piRNA production. Science. 2015:348(6236):817-21.

51. Homolka D, Pandey RR, Goriaux C, Brasset E, Vaury C, Sachidanandam R, Fauvarque MO, Pillai RS. PIWI slicing and RNA elements in precursors instruct directional primary piRNA biogenesis. Cell Rep. 2015;12(3):418-28.

52. Mohn F, Handler D, Brennecke J. Noncoding RNA. piRNA-guided slicing specifies transcripts for Zucchini-dependent, phased piRNA biogenesis. Science. 2015;348(6236):812-7.

53. Ding D, Liu J, Dong K, Melnick AF, Latham KE, Chen C. Mitochondrial membrane-based initial separation of MIWI and MILI functions during pachytene piRNA biogenesis. Nucleic Acids Res. 2019;47(5):2594-608.

54. Wenda JM, Homolka D, Yang Z, Spinelli P, Sachidanandam R, Pandey RR, Pillai RS. Distinct roles of RNA helicases MVH and TDRD9 in PIWI slicing-triggered mammalian piRNA biogenesis and function. Dev Cell. 2017:41(6):623-37.

55. De Fazio S, Bartonicek N, Di Giacomo M, Abreu-Goodger C, Sankar A, Funaya C, Antony C, Moreira PN, Enright AJ, O'Carroll D. The endonuclease activity of Mili fuels piRNA amplification that silences LINE1 elements. Nature. 2011:480(7376):259-63.

56. Yang Z, Chen KM, Pandey RR, Homolka D, Reuter M, Janeiro BK, Sachidanandam R, Fauvarque MO, McCarthy AA, Pillai RS. PIWI slicing and EXD1 drive biogenesis of nuclear piRNAs from cytosolic targets of the mouse piRNA pathway. Mol Cell. 2016;61(1):138-52.

57. Esposito T, Magliocca S, Formicola D, Gianfrancesco F. piR_015520 belongs to Piwi-associated RNAs regulates expression of the human melatonin receptor 1A gene. PLoS ONE. 2011;6(7):e22727.

58. Fathizadeh $H$, Asemi Z. Epigenetic roles of PIWI proteins and piRNAs in lung cancer. Cell Biosci. 2019;9:102. https://doi.org/10.1186/s1357 8-019-0368-x

59. Feldman N, Gerson A, Fang J, Li E, Zhang Y, Shinkai Y, Cedar H, Bergman Y. G9a-mediated irreversible epigenetic inactivation of Oct-3/4 during early embryogenesis. Nat Cell Biol. 2006;8(2):188-94.

60. Wang QX, Zhu YQ, Zhang H, Xiao J. Altered MiRNA expression in gastric cancer: a systematic review and meta-analysis. Cell Physiol Biochem. 2015;35(3):933-44.

61. Hale BJ, Yang CX, Ross JW. Small RNA regulation of reproductive function. Mol Reprod Dev. 2014;81(2):148-59. 
62. Peng L, Song L, Liu C, Lv X, Li X, Jie J, Zhao D, Li D. piR-55490 inhibits the growth of lung carcinoma by suppressing mTOR signaling. Tumour Biol. 2016;37(2):2749-56

63. Lee EJ, Banerjee S, Zhou H, Jammalamadaka A, Arcila M, Manjunath BS, Kosik KS. Identification of piRNAs in the central nervous system. RNA. 2011;17(6):1090-9.

64. Rajasethupathy P, Antonov I, Sheridan R, Frey S, Sander C, TuschI T, Kandel ER. A role for neuronal piRNAs in the epigenetic control of memoryrelated synaptic plasticity. Cell. 2012;149(3):693-707.

65. Yan Z, Hu HY, Jiang X, Maierhofer V, Neb E, He L, Hu Y, Hu H, Li N, Chen W, et al. Widespread expression of piRNA-like molecules in somatic tissues. Nucleic Acids Res. 2011;39(15):6596-607.

66. Wilson AS, Power BE, Molloy PL. DNA hypomethylation and human diseases. Biochim Biophys Acta. 2007;1775(1):138-62.

67. Kuramochi-Miyagawa S, Watanabe T, Gotoh K, Takamatsu K, Chuma S, Kojima-Kita K, Shiromoto Y, Asada N, Toyoda A, Fujiyama A, et al. MVH in piRNA processing and gene silencing of retrotransposons. Genes Dev. 2010;24(9):887-92.

68. Aravin AA, Sachidanandam R, Bourc'his D, Schaefer C, Pezic D, Toth KF, Bestor T, Hannon GJ. A piRNA pathway primed by individual transposons is linked to de novo DNA methylation in mice. Mol Cell. 2008;31(6):785-99.

69. Liu J, Zhang S, Cheng B. Epigenetic roles of PIWlinteracting RNAs (piRNAs) in cancer metastasis (Review). Oncol Rep. 2018:40(5):2423-34.

70. Weng W, Liu N, Toiyama Y, Kusunoki M, Nagasaka T, Fujiwara T, Wei Q, Qin $H$, Lin H, Ma Y, et al. Novel evidence for a PIWl-interacting RNA (piRNA) as an oncogenic mediator of disease progression, and a potential prognostic biomarker in colorectal cancer. Molecular cancer. 2018;17(1):16.

71. Ferreira HJ, Heyn H. Garcia del Muro X, Vidal A, Larriba S, Munoz C, Villanueva A, Esteller M: Epigenetic loss of the PIWI/piRNA machinery in human testicular tumorigenesis. Epigenetics. 2014:9(1):113-8.

72. Sell S. Cancer stem cells and differentiation therapy. Tumour Biol. 2006;27(2):59-70.

73. Esteller M. Cancer epigenomics: DNA methylomes and histone-modification maps. Nat Rev Genet. 2007:8(4):286-98.

74. Simon JA, Lange CA. Roles of the EZH2 histone methyltransferase in cancer epigenetics. Mutat Res. 2008;647(1-2):21-9.

75. Tsang DP, Cheng AS. Epigenetic regulation of signaling pathways in cancer: role of the histone methyltransferase EZH2. J Gastroenterol Hepatol. 2011;26(1):19-27.

76. Siddiqi S, Matushansky I. Piwis and piwi-interacting RNAs in the epigenetics of cancer. J Cell Biochem. 2012:113(2):373-80.

77. Han YN, Li Y, Xia SQ, Zhang YY, Zheng JH, Li W. PIWI Proteins and PIWI-Interacting RNA: Emerging Roles in Cancer. Cell Physiol Biochem. 2017;44(1):1-20.

78. Fu A, Jacobs DI, Hoffman AE, Zheng T, Zhu Y. PIWI-interacting RNA 021285 is involved in breast tumorigenesis possibly by remodeling the cancer epigenome. Carcinogenesis. 2015;36(10):1094-102.
79. Tan L, Mai D, Zhang B, Jiang X, Zhang J, Bai R, Ye Y, Li M, Pan L, Su J, et al. PIWI-interacting RNA-36712 restrains breast cancer progression and chemoresistance by interaction with SEPW1 pseudogene SEPW1P RNA. Mol Cancer. 2019;18(1):9.

80. Gou LT, Dai P, Yang JH, Xue Y, Hu YP, Zhou Y, Kang JY, Wang X, Li H, Hua $M M$, et al. Pachytene piRNAs instruct massive mRNA elimination during late spermiogenesis. Cell Res. 2014;24(6):680-700.

81. Rouget C, Papin C, Boureux A, Meunier AC, Franco B, Robine N, Lai EC, Pelisson A, Simonelig M. Maternal mRNA deadenylation and decay by the piRNA pathway in the early Drosophila embryo. Nature. 2010;467(7319):1128-32.

82. Hashim A, Rizzo F, Marchese G, Ravo M, Tarallo R, Nassa G, Giurato G, Santamaria G, Cordella A, Cantarella C, et al. RNA sequencing identifies specific PIWI-interacting small non-coding RNA expression patterns in breast cancer. Oncotarget. 2014;5(20):9901-10.

83. Huang G, Hu H, Xue X, Shen S, Gao E, Guo G, Shen X, Zhang X. Altered expression of piRNAs and their relation with clinicopathologic features of breast cancer. Clin Transl Oncol. 2013;15(7):563-8.

84. Carter CL, Allen C, Henson DE. Relation of tumor size, lymph node status, and survival in 24,740 breast cancer cases. Cancer. 1989;63(1):181-7.

85. Zhang H, Ren Y, Xu H, Pang D, Duan C, Liu C. The expression of stem cell protein Piwil2 and piR-932 in breast cancer. Surg Oncol. 2013;22(4):217-23.

86. Wang Z, Liu N, Shi S, Liu S, Lin H. The Role of PIWIL4, an Argonaute Family Protein. Breast Cancer J Biol Chem. 2016:291(20):10646-58.

87. Kwon C, Tak H, Rho M, Chang HR, Kim YH, Kim KT, Balch C, Lee EK, Nam S. Detection of PIWI and piRNAs in the mitochondria of mammalian cancer cells. Biochem Biophys Res Commun. 2014;446(1):218-23.

88. Chen C, Liu J, Xu G. Overexpression of PIWI proteins in human stage III epithelial ovarian cancer with lymph node metastasis. Cancer Biomark. 2013;13(5):315-21.

89. Suzuki R, Honda S, Kirino Y. PIWI expression and function in cancer. Front Genet. 2012;3:204

90. Wang Y, Liu Y, Shen X, Zhang X, Chen X, Yang C, Gao H. The PIWI protein acts as a predictive marker for human gastric cancer. Int J Clin Exp Pathol. 2012;5(4):315-25

91. Qiao D, Zeeman AM, Deng W, Looijenga LH, Lin H. Molecular characterization of hiwi, a human member of the piwi gene family whose overexpression is correlated to seminomas. Oncogene. 2002;21(25):3988-99.

92. Lee JH, Jung C, Javadian-Elyaderani P, Schweyer S, Schutte D, Shoukier M, Karimi-Busheri F, Weinfeld M, Rasouli-Nia A, Hengstler JG, et al. Pathways of proliferation and antiapoptosis driven in breast cancer stem cells by stem cell protein piwil2. Cancer Res. 2010;70(11):4569-79.

\section{Publisher's Note}

Springer Nature remains neutral with regard to jurisdictional claims in published maps and institutional affiliations.
Ready to submit your research? Choose BMC and benefit from:

- fast, convenient online submission

- thorough peer review by experienced researchers in your field

- rapid publication on acceptance

- support for research data, including large and complex data types

- gold Open Access which fosters wider collaboration and increased citations

- maximum visibility for your research: over $100 \mathrm{M}$ website views per year

At BMC, research is always in progress.

Learn more biomedcentral.com/submissions 